\title{
Artikel
}

\section{Procederen ten behoeve van de gemeenschap van nalatenschap}

Prof. dr. S. Perrick*

\section{Inleiding}

In de praktijk komt het regelmatig voor dat een erfgenaam procedeert ten behoeve van de gemeenschap van een nalatenschap zonder dat deze deelgenoot zich realiseert dat hij dat ten behoeve van de gemeenschap doet. Ten behoeve van de leesbaarheid van dit artikel ga ik er in het vervolg van uit dat het gaat om een nalatenschap met twee erfgenamen. Dan spreekt de problematiek ook het duidelijkst. Het kan daarbij gaan om een overeenkomst die erflater met een erfgenaam heeft gesloten en waarmee de andere erfgenaam/deelgenoot problemen heeft, en die de andere deelgenoot wil vernietigen, bijvoorbeeld op de grond dat de overeenkomst door bedrog of misbruik van omstandigheden tot stand is gekomen. Ook kan het gaan om een vordering van de nalatenschap uit hoofde van een door erflater met een erfgenaam aangegane leningsovereenkomst. De vordering kan verder onder meer zijn gebaseerd op een door een erfgenaam jegens erflater gepleegde onrechtmatige daad. De erfgenaam die de overeenkomst wil vernietigen, of tegen zijn mede-erfgenaam een rechtsvordering wil instellen op grond van bijvoorbeeld onrechtmatige daad, heeft regelmatig het gevoel dat hij dat ten behoeve van zichzelf doet, en hetzelfde geldt voor zijn advocaat. Maar de eventuele rechtsvordering tot vernietiging van de door erflater gesloten overeenkomst of de vordering uit hoofde van onrechtmatige daad kwam toe aan erflater en behoort na diens overlijden tot de gemeenschap van nalatenschap. En dat

* Prof dr. S. Perrick is advocaat te Amsterdam. betekent dat aan de hand van titel 3.7 van het Burgerlijk Wetboek (BW) en de rechtspraak van de Hoge Raad dient te worden vastgesteld wie ter zake bevoegd is ten behoeve van de gemeenschap van nalatenschap te procederen. Ook in het geval dat een deelgenoot ten behoeve van de gemeenschap (mede) een rechtsvordering wil instellen tegen een ander dan een deelgenoot, geeft titel 3.7 BW het antwoord op de vraag of hij daartoe bevoegd is.

Het kan ook voorkomen dat de vordering van erflater behoort tot een door zijn overlijden ontbonden huwelijksgemeenschap. Ook dan geldt het vorenstaande, waarbij men zich realisere dat tot de ontbonden huwelijksgemeenschap zijn gerechtigd de langstlevende en, in mijn voorbeeld, de twee erfgenamen. Zie daarover paragraaf 6 . Ik behandel de problematiek eerst zonder in aanmerking te nemen dat er een executeur in functie is, dat er een (afwikkelings)bewind is ingesteld, of dat de gemeenschap overeenkomstig afdeling 4.6.3 $\mathrm{BW}$ dient te worden vereffend. Zie voor deze gevallen paragraaf 4 en 5 .

\section{Procederen ten behoeve van de gemeenschap is een beheershandeling. Algemeen}

Onder procederen ten behoeve van de gemeenschap dient allereerst te worden verstaan 'het instellen van rechtsvorderingen en het indienen van verzoekschriften ter verkrijging van een rechterlijke uitspraak ten behoeve van de gemeenschap'. De passage tussen aanhalingstekens ontleen ik aan artikel 3:171 eerste volzin BW. 
Ook het voeren van verweer tegen rechtsvorderingen die tegen de gemeenschap zijn ingesteld of in een procedure waarbij de gemeenschap gerekwestreerde is, is een beheershandeling.

Dit betekent dat de deelgenoten volgens deze hoofdregel, de lex generalis, slechts gezamenlijk bevoegd zijn om ten behoeve van de gemeenschap te procederen, tenzij - en dat is in het bijzonder voor de advocatuur belangrijk om te onderkennen - een beheersregeling anders bepaalt. Hierop bestaat een uitzondering indien de processuele handeling geen uitstel kan lijden. Daarvan kan in het bijzonder sprake zijn in het geval de gemeenschap gedaagde of gerekwestreerde is. Een beheersregeling kan door de deelgenoten worden overeengekomen en kan bij gebreke van een dergelijke overeenkomst door de kantonrechter worden vastgesteld op verzoek van de meest gerede partij, lees in dit geval: iedere deelgenoot. Zie artikel 3:168 lid 1 en 2 BW.

Heeft de gemeenschap een vordering op een deelgenoot en is deze niet bereid deze schuld voorafgaande aan de verdeling te voldoen, dan zal de deelgenoot/schuldenaar ook wel niet willen meewerken aan het overeenkomen van een beheersregeling. De andere deelgenoot kan de kantonrechter dan verzoeken een beheersregeling vast te stellen. Deze regeling kan beperkt zijn tot het ten behoeve van de gemeenschap tegen de deelgenoot/ schuldenaar procederen en het eventueel namens de gemeenschap in ontvangst nemen van de aan de gemeenschap verschuldigde prestatie. Dat laatste is volgens artikel 3:170 lid 2 tweede volzin BW ook een beheershandeling waartoe de deelgenoten in beginsel slechts gezamenlijk bevoegd zijn. De kantonrechter kan de andere deelgenoot of een derde als beheerder aanwijzen. Ook indien het gaat om een vordering op een deelgenoot die in de verdeling van de gemeenschap kan worden betrokken, betekent dit niet dat de gemeenschap niet voorafgaande aan de verdeling tegen die deelgenoot een rechtsvordering kan instellen. ${ }^{1}$ Het instellen van een dergelijke rechtsvordering mag niet in strijd zijn met hetgeen de redelijkheid en billijkheid eisen. Van een dergelijke strijd zal onder meer geen sprake zijn indien de voldoening van een geldschuld aan de gemeenschap nodig is teneinde (belasting)schulden te kunnen voldoen. En ook niet voor zover de schuld van een deelgenoot meer bedraagt dan zijn aandeel in de gemeenschap, want in zoverre kan bij de verdeling geen gedwongen schadeverrekening plaatsvinden.

Ook in een geval dat de gemeenschap gedaagde of gerekwestreerde is, kan het wenselijk zijn dat de kantonrechter een beheersregeling vaststelt die erin voorziet dat een van de deelgenoten, of een derde, privatief bevoegd is tot het voeren van verweer. Hierbij is onder meer te denken aan de situatie dat een van de deelgenoten of een familielid pretendeert een vordering op de gemeenschap te hebben.
In dit artikel besteed ik hoofdzakelijk aandacht aan het ten behoeve van de gemeenschap procederen waarbij de gemeenschap eiser of verzoeker is. ${ }^{2}$

\section{Procederen ten behoeve van de gemeenschap: een lex specialis}

Volgens artikel 3:171 BW is iedere deelgenoot bevoegd tot het instellen van rechtsvorderingen en het indienen van verzoekschriften ter verkrijging van een rechterlijke uitspraak ten behoeve van de gemeenschap. Tenzij een regeling anders bepaalt. Een regeling die het beheer toekent aan één of meer deelgenoten sluit, tenzij anders bepaald, deze bevoegdheid voor de andere deelgenoten uit. De in artikel 3:171 BW neergelegde regeling berust naar mijn mening op een ongelukkige keuze van de wetgever. ${ }^{3}$ Deze regel kan ertoe leiden dat een rechterlijke uitspraak gezag van gewijsde heeft ten aanzien van een deelgenoot die aan de procedure part noch deel heeft gehad. ${ }^{4}$

Artikel 3:171 BW heeft geen betrekking op rechtsvorderingen die tegen de gemeenschap zijn ingesteld of op verzoekschriften waarbij de gemeenschap gerekwestreerde is.

De bepaling moge een ongelukkige regeling bevatten, zij is wel in de wet opgenomen en de rechter kan er dan ook niet omheen. De Hoge Raad past de bepaling dan ook toe en in twee arresten heeft hij beslissingen gegeven over vragen waartoe deze bepaling aanleiding heeft gegeven. Allereerst in HR 8 september 2000, NJ 2000/604. In dit arrest besliste de Hoge Raad dat de deelgenoot die een uitspraak ten behoeve van de gemeenschap wil uitlokken in de dagvaarding of het verzoekschrift kenbaar moet maken dat hij in zijn hoedanigheid voor de gezamenlijke, zo veel mogelijk met name genoemde, deelgenoten optreedt. In dit arrest heeft de Hoge Raad voorts beslist dat artikel 3:171 BW uitsluitend ziet op vorderingen tegen derden en niet op vorderingen tegen een andere deelgenoot. Dit oordeel heeft de Hoge Raad herhaald in HR 6 april 2018, NJ 2018/308. ${ }^{5}$ In dit laatste arrest motiveert de Hoge Raad duidelijker dan in het arrest van 8 september 2000 waarom dit naar zijn oordeel zo is. Vorderingen en verzoeken tegen een deelgenoot dienen volgens de Hoge Raad 'immers' op de voet van artikel 3:184 en 3:185 BW in de verdeling van de gemeenschap te worden betrokken.

Op de tenuitvoerlegging van een executoriale titel strekkende tot betaling van een schuld van de nalatenschap ben ik ingegaan in een artikel in WPNR 2012/6938.

Zie Asser/Perrick 3-V 2015/29

Zie HR 24 april 1992, ECLI:NL:HR:1992:ZC0586, NJ 1992/461.

Met een noot van mijn hand in NJ. Zie over dit arrest ook J.H. Lieber, De slag om de Klaaswaalse landerijen. Eén voor allen of allen tegen één? Procederen namens en in een nalatenschap, Tijdschrift Erfrecht 2018/5, p. 145 e.v., van wiens bijdrage ik eerst na het schrijven van dit artikel heb kennisgenomen. 
Dat laatste is naar mijn mening een onvoldoende argument om een deelgenoot niet bevoegd te achten ten behoeve van de gemeenschap tegen een deelgenoot te procederen. Mijns inziens dient deze problematiek anders te worden benaderd. Indien het niet in strijd is met de eisen van de redelijkheid en billijkheid dat de gemeenschap voorafgaand aan de verdeling tegen een deelgenoot procedeert, dan is artikel 3:171 BW van toepassing. Hierboven heb ik in paragraaf 2 omstandigheden genoemd waarin het niet onredelijk is dat, voorafgaande aan de verdeling van de gemeenschap, ten behoeve van de gemeenschap een rechtsvordering wordt ingesteld tot betaling van een opeisbare schuld van een deelgenoot. En indien de rechtsvordering strekt tot vernietiging van een rechtshandeling, bijvoorbeeld een overeenkomst die erflater met een deelgenoot is aangegaan, dan verdient het naar mijn mening de voorkeur dat voorafgaande aan de verdeling door de rechter wordt beslist of de rechtshandeling voor vernietiging in aanmerking komt. En daartoe bevorderlijk is dat de rechtsvordering tot vernietiging voorafgaande aan de verdeling wordt ingesteld. Maar daarvan wil de Hoge Raad niet weten. In het arrest van 6 april 2018 vorderde een van de deelgenoten/erfgenamen vernietiging van twee overeenkomsten die erflater met haar broer, een andere deelgenoot/erfgenaam, en diens drie dochters had gesloten. De Hoge Raad sanctioneert het oordeel van het hof dat eiseres in haar vordering jegens haar broer niet-ontvankelijk is, omdat artikel 3:171 $\mathrm{BW}$ niet ziet op vorderingen jegens een deelgenoot. Maar ook indien men het door de Hoge Raad gehanteerde enge en naar mijn mening onjuiste criterium hanteert, is het mij niet duidelijk hoe de rechtsvorderingen die strekken tot vernietiging van overeenkomsten zich ervoor lenen in de verdeling te worden betrokken. ${ }^{6}$ Overigens meen ik dat de oordelen van de Hoge Raad in het arrest van 6 april 2018 extra onbevredigend zijn in verband met het navolgende. ${ }^{7}$ Volgens de Hoge Raad was zuster wel ontvankelijk in haar rechtsvordering tegen de dochters van haar broer, die niet deelgenoten/erfgenamen zijn. Maar de overeenkomst waarbij, behalve erflater, broer en zijn dochters partij waren, en tot vernietiging waarvan de rechtsvordering strekt, kan slechts worden vernietigd in een procedure waarbij alle partijen, waaronder begrepen broer, bij de overeenkomst zijn betrokken. Dus de ontvankelijkheid van zuster jegens de kleindochters van erflater kan haar niet baten. Alleen dit gegeven al had de Hoge Raad naar mijn mening tot het oordeel dienen te

6. Ook de A-G - in 2.26-2.27 van zijn conclusie - meent dat de vernietigingsvordering niet in de verdeling kan worden betrokken, maar dat de eventueel aan broer toegekomen meerwaarde kan worden rechtgetrokken in de vorm van gedwongen toerekening. Deze route biedt echter geen oplossing voor de bevoordeling van de dochters van broer, die geen deelgenoten zijn in de nalatenschap van erflater. Terwijl zuster ook niet ten behoeve van de gemeenschap kan bewerkstelligen dat de overeenkomsten waardoor kleindochters zijn bevoordeeld, worden vernietigd

7. Ik abstraheer in het navolgende van het door de Hoge Raad gesanctioneerde oordeel van het hof dat de rechtsvorderingen van zuster jegens de dochters van broer waren verjaard. brengen dat zuster ook ontvankelijk dient te zijn in haar rechtsvorderingen jegens haar broer.

De praktijk dient ervan uit te gaan dat een deelgenoot die ten behoeve van de gemeenschap een rechtsvordering instelt tegen een deelgenoot spoedig niet-ontvankelijk zal worden verklaard. Hij dient de veilige weg te volgen en de kantonrechter te verzoeken een beheersregeling vast te stellen waarin hij bevoegd wordt verklaard ter zake ten behoeve van de gemeenschap te procederen. Dienen ook één of meer niet-deelgenoten in de procedure te worden betrokken, dan kan de beheersregeling ook daarin voorzien.

\section{$4 \mathrm{Er}$ is een executeur of vereffenaar in functie}

Indien er een executeur of vereffenaar in functie is, komt aan deze het beheer over de gemeenschap van nalatenschap toe. Dat betekent dat uitsluitend de executeur of de vereffenaar ten behoeve van de gemeenschap kan procederen. Daarbij vertegenwoordigen de executeur en de vereffenaar de erfgenamen. Zie artikel 4:145 lid 2 BW onderscheidenlijk artikel 4:211 lid 2 BW. ${ }^{8}$

Is de nalatenschap door één of meer erfgenamen beneficiair aanvaard en zijn de erfgenamen uit dien hoofde de vereffenaars, dan oefenen de erfgenamen hun bevoegdheden als vereffenaars gezamenlijk uit, zo bepaalt artikel 4:198 BW. Artikel 3:171 BW is, zo volgt uit artikel 4:222 $\mathrm{BW}$, niet van toepassing. Gaat het om een ten behoeve van de gemeenschap van nalatenschap in te stellen rechtsvordering tegen een erfgenaam/vereffenaar, dan dient die rechtsvordering derhalve te worden ingesteld door de erfgenamen/vereffenaars tezamen. Artikel 4:198 BW verklaart de kantonrechter bevoegd 'anders' te bepalen, dat wil in dit geval zeggen: te bepalen dat de rechtsvordering tegen een erfgenaam/vereffenaar kan worden ingesteld zonder de medewerking van deze erfgenaam/vereffenaar.

\section{Er is een bewindvoerder in functie}

Volgens artikel 4:166 BW komt het beheer uitsluitend toe aan de bewindvoerder. ${ }^{9}$ Dat betekent dat de bewindvoerder met uitsluiting van de rechthebbende(n) bevoegd is ten behoeve van de gemeenschap te procederen. Die bevoegdheid is onderdeel van de bevoegdheid

8. Voor een tegen de gemeenschap in te stellen rechtsvordering is art. 53 Rv van belang. Zie daarover mijn in noot 2 genoemde WPNR-artikel.

9. De rechthebbende is naast de bewindvoerder bevoegd tot handelingen dienende tot gewoon onderhoud van de goederen die hij in gebruik heeft en tot handelingen die geen uitstel kunnen lijden. Ik ga ervan uit dat erflater de beheersbevoegdheid van de bewindvoerder niet op de voet van art. 4:171 BW heeft beperkt. 
tot beheer en artikel 4:173 eerste volzin BW bepaalt naar mijn mening dan ook ten overvloede dat de bewindvoerder de rechthebbende vertegenwoordigt in gedingen ter zake van onder het bewind staande goederen. ${ }^{10}$ Deze, op zichzelf overbodige, bepaling is nuttig omdat zij vooruitloopt op de overige twee bepalingen van artikel 4:173 $\mathrm{BW}$, die enige zin hebben. Volgens de tweede bepaling kan de bewindvoerder zich, alvorens in rechte op te treden, te zijner verantwoording doen machtigen door de rechthebbende en degenen in wier belang het bewind uitsluitend of mede is ingesteld. Wordt de machtiging niet verleend, dan kan de kantonrechter haar door zijn machtiging vervangen (art. 4:173 derde zin BW). De ratio legis van deze bepalingen is niet overtuigend. De daar bedoelde machtiging kan uiteraard niet voorkomen dat de bewindvoerder jegens de rechthebbende of een belanghebbende aansprakelijk is indien hij bij het procederen in de zorg van een goed bewindvoerder tekortschiet. En in vele andere gevallen zal de bewindvoerder keuzes dienen te maken waarbij aan hem een zekere beleidsvrijheid toekomt, en waarbij de wet niet voorziet in de mogelijkheid van een machtiging 'te zijner verantwoording'.

Tot slot signaleer ik hier aan de hand van een voorbeeld een probleem. Tot de onder bewind staande goederen van de gemeenschap behoort een vordering van de gemeenschap op de bewindvoerder. De bewindvoerder is in verzuim met de voldoening van deze schuld en is niet bereid als bewindvoerder rechtsmaatregelen tegen zichzelf als schuldenaar te nemen. Naar mijn mening vormt dat een gewichtige reden voor ontslag door de kantonrechter op grond van artikel 4:165 BW.

Zijn niet de goederen van de gemeenschap onder bewind gesteld, maar een aandeel in de goederen, dan geldt het vorenstaande mutatis mutandis. De bewindvoerder over een aandeel in een goed is op grond van artikel 3:171 BW bevoegd ten behoeve van de gemeenschap te procederen, waarbij rekening dient te worden gehouden met de door de Hoge Raad aangenomen beperkingen. Alvorens dat te doen, kan hij zich op de voet van artikel 4:173 BW doen machtigen. Onder het beheer van de bewindvoerder valt het doen van een verzoek aan de kantonrechter om een beheersregeling voor de gemeenschap te treffen.

Het meerderjarigenbewind van titel $1.19 \mathrm{BW}$ kan van belang zijn indien dit bewind mede is ingesteld over goederen die aan de rechthebbende zullen toebehoren, waaronder begrepen een hem toekomend erfdeel in een nalatenschap. Ik volsta hier met het volgende. Volgens artikel 1:438 lid 1 BW komt tijdens het bewind het beheer over de onder bewind staande goederen aan de bewindvoerder toe. En artikel 4:441 lid 1 BW bepaalt dat de bewindvoerder bij de vervulling van zijn taak de rechthebbende in en buiten rechte vertegenwoordigt. In artikel 1:443 BW treffen wij de met artikel 4:173 BW overeenkomende regel aan dat de bewindvoerder zich,

10. Deze bevoegdheid dient ruim te worden opgevat. Zie Asser/Perrick 4 $2017 / 749$. alvorens in rechte op te treden, te zijner verantwoording kan doen machtigen door de rechthebbende of, indien deze daartoe niet in staat of weigerachtig is, door de kantonrechter.

\section{De ontbonden huwelijksgemeenschap}

Artikel 3:170 en 3:171 BW zijn ook van toepassing op de ontbonden huwelijksgemeenschap, ${ }^{11}$ zowel in het geval de twee (ex-)echtgenoten de deelgenoten zijn als in het geval dat de huwelijksgemeenschap door het overlijden van een van de echtgenoten is ontbonden en (een deel van) de nalatenschap omvat. Dat laatste zal zich uiteraard slechts voordoen indien er sprake is van een ontbonden huwelijksgemeenschap en zich niet het geval voordoet dat de langstlevende ten gevolge van de wettelijke verdeling uitsluitend gerechtigd is geworden tot alle goederen van de ontbonden huwelijksgemeenschap.

Is er over de goederen van de nalatenschap, waaronder het aandeel van de helft in de goederen van de ontbonden huwelijksgemeenschap, een bewind ingesteld, dan komt aan de langstlevende en de bewindvoerder gezamenlijk het beheer van de goederen van de huwelijksgemeenschap toe. Aan ieder van hen komt de bevoegdheid toe op de voet van artikel 3:171 BW ten behoeve van de gemeenschap te procederen.

Fungeert er een executeur of vereffenaar van de nalatenschap. dan geldt hetzelfde. ${ }^{12}$

\section{Conclusies}

Dit artikel heb ik in het bijzonder ter voorlichting van advocaten geschreven. Recentelijk heb ik een aantal keren geconstateerd dat een advocaat voor een erfgenaam tegen een mede-erfgenaam procedeert over een vordering die erflater volgens eiser op de mede-erfgenaam heeft. Het gaat daarbij in het bijzonder om vorderingen uit overeenkomst, daaronder begrepen de rechtsvorderingen tot vernietiging, onverschuldigde betaling en onrechtmatige daad. Zeker als er maar één mede-erfgenaam is, 'voelt' het voor de eiser alsof hij privé procedeert tegen zijn mede-erfgenaam. Maar het gaat om een (gepretendeerde) vordering van de gemeenschap. Als hij zich dat realiseert en ook heeft vastgesteld dat de redelijkheid en billijkheid zich er niet tegen verzetten dat hij voorafgaande aan de verdeling tegen een mededeelgenoot een rechtsvordering instelt, dient hij de kantonrechter te verzoeken een beheersregeling te treffen en

11. En ook voor een ontbonden gemeenschap van maatschap of vennootschap. HR 8 september 2000, ECLI:NL:HR:2000:AA7043, NJ 2000/604 had betrekking op een ontbonden gemeenschap van vennootschap.

12. Zie ook art. 4:213 BW, dat aan de vereffenaar van de nalatenschap de bevoegdheid toekent om de rechtbank te verzoeken een vereffenaar van de ontbonden huwelijksgemeenschap te benoemen. 
hem als beheerder aan te wijzen. Daaraan ontleent hij de bevoegdheid ter zake van de gemeenschappelijke vordering tegen zijn mededeelgenoot te procederen. Dat is van belang omdat op grond van (recente) jurisprudentie van de Hoge Raad dient te worden aangenomen dat de rechter hem niet spoedig bevoegd zal achten op de voet van artikel 3:171 BW ten behoeve van de gemeenschap tegen zijn mededeelgenoot te procederen.

Een dergelijk verzoek zal niet kunnen worden toegewezen indien er een executeur, vereffenaar of bewindvoerder in functie is. Daaraan bestaat dan ook geen behoefte. 